\title{
FACES DA DESIGUALDADE: OS EFEITOS DA CIRCULAÇÃO DE RETRATOS DE CRIANÇAS DESAPARECIDAS NO BRASIL
}

\section{Faces of inequality: the effects of the circulation of missing children posters in Brazil}

\author{
Leticia Carvalho de Mesquita Ferreira* \\ * Escola de Ciências Sociais/CPDOC, Fundação Getúlio Vargas (FGV) (Brasil) \\ leticiacarvalho@gmail.com
}

Palavras chave

Desaparecimento Crianças e adolescentes Fotografias Intervenção

\begin{abstract}
Resumo
Em 1996 foi criado, no Rio de Janeiro, u.m serviço público especializado no desaparecimento de crianças e adolescentes: o SOS Crianças Desaparecidas. A criação do SOS atendeu a determinações da lei federal brasileira conhecida como Estatuto da Criança e do Adolescente, e respondeu à crescente importância conferida, sobretudo por meio da luta de familiares de vítimas, ao fenômeno do desaparecimento de pessoas no Brasil. A partir de pesquisa etnográfica realizada nas dependências do SOS, o artigo trata dos múltiplos efeitos provocados por uma das principais ações realizadas pelos assistentes sociais que trabalham no serviço: a divulgação sistemática de retratos de meninas e meninos desaparecidos, realizada por meio de convênios com ONGs, associações de familiares de desaparecidos, empresas e outros parceiros. Argumento que a difusão de fotografias de desaparecidos provoca efeitos não apenas na trajetória particular de cada desaparecimento assim divulgado, mas também nas biografias de outras crianças e adolescentes não diretamente envolvidos nos casos, que se tornam alvo de intervenções por parte de serviços e órgãos públicos. Mais especificamente, busco demonstrar o papel tão sutil quanto determinante de certas categorias e julgamentos morais na definição de quais outras crianças e adolescentes além das vítimas de desaparecimento podem terminar por sofrer intervenções em consequência da circulação de retratos de meninas e meninos desaparecidos.
\end{abstract}

\section{Abstract}

In 1996, a public service specialized in missing children was created in Rio de Janeiro: "SOS Crianças Desaparecidas". The creation of SOS met the requirements of the Brazilian federal law known as the Statute of the Child and Adolescent, and responded to the growing relevance assigned to the phenomenon of missing people in Brazil, especially through the activism of relatives of victims. Drawing from ethnographic research, the paper focuses on the multiple effects caused by one of the main actions carried out by social workers working in SOS: the systematic dissemination of portraits of missing girls and boys, carried out through agreements with NGOs, associations of relatives of missing persons, companies and other partners. I argue that the dissemination of photographs of missing persons has effects not only on the particular trajectory of each case of disappearance thus disseminated, but also on the biographies of other children and adolescents that, though not directly involved in the cases, end up being submitted to interventions by public services and agencies. More specifically, I try to unveil the subtle and determinant role of certain categories and moral judgments in the definition of which other children and adolescents other than victims of disappearance may end up suffering those interventions as a result of the circulation of missing girls and boys portraits.

Carvalho de Mesquita Ferreira, L. (2017). Faces da desigualdade: os efeitos da circulação de retratos de crianças desaparecidas no Brasil. Papeles del CEIC. International Journal on Collective Identity Research, vol. 2017/1, papel 171, CEIC (Centro de Estudios sobre la Identidad Colectiva), UPV/EHU Press, http://dx.doi.org/10.1387/pceic.16917

Recibido: 8/2016; Aceptado: 1/2017 


\section{INTRODUÇÃO}

A promulgação do Estatuto da Criança e do Adolescente (ECA), como bem demonstram os trabalhos de Cardarello (1996), Gregori e Silva (2000), Vianna (2002) e Schuch (2003, 2009), marcou uma importante inflexão nos princípios que até então regiam práticas, representações e tecnologias de governo voltadas para a infância e a juventude no Brasil. ${ }^{1}$ Atribuindo a nossas crianças e adolescentes o estatuto de sujeitos de direitos, o ECA veio substituir a chamada doutrina da situação irregular pela doutrina da proteção integral. Ao fazê-lo, introduziu no país um novo regime discursivo em torno da infância e da juventude e, nesse sentido, informou a criação de um conjunto específico de normas, instituições e serviços destinados à sua proteção. Afinada com a difusão internacional dos chamados direitos da criança, parte da disseminação mais ampla da retórica universalista dos direitos humanos, a introdução desse novo regime discursivo no país não se fez sem ambivalências e paradoxos. Afinal, como os trabalhos citados revelam, "por um lado temos uma lei considerada avançada em suas posições igualitárias e universalizantes (ECA) e, por outro lado, uma prática de intervenção estatal que toma a desigualdade social como variável determinante para a penalização da pobreza" (Schuch, 2003: 194) e para outros processos duradouros envolvendo a infância e a juventude no Brasil.

Parte das ambivalentes inovações promovidas pelo Estatuto, que incide diretamente sobre a nova "trama institucional" (Gregori e Silva, 2000) formada a partir de sua promulgação, é a determinação de que uma das linhas da política de atendimento à criança e ao adolescente no Brasil deve ser a provisão de serviços "de identificação e localização de pais, responsável, crianças e adolescentes desaparecidos" (ECA, artigo 87, IV). Ao integrar o ECA, essa determinação logrou destacar as crianças e os adolescentes desaparecidos dentre todas as crianças e adolescentes cujos direitos devem ser prioritariamente garantidos no país. No mesmo movimento, logrou também conferir importância inédita a um fenômeno até então pouco debatido em território nacional, o desaparecimento de crianças e adolescentes ${ }^{2}$, e a uma categoria

\footnotetext{
${ }^{1}$ O Estatuto da Criança e do Adolescente é a lei 8.069, de 13 de julho de 1990.

${ }^{2}$ Algumas iniciativas, programas e instrumentos normativos criados no Brasil e em diferentes unidades da federação que evidenciam a importância desde então conferida ao fenômeno são o projeto "Caminho de Volta", desenvolvido na Faculdade de Medicina da Universidade de São Paulo, em parceira com a Secretaria de Segurança Pública daquele estado, desde 2004; a Rede Nacional para Identificação e Localização de Crianças
} 
controversa, cujo estatuto administrativo e legal permanece em debate no país: as pessoas desaparecidas ${ }^{3}$.

Atendendo a essa determinação da legislação e respondendo à importância desde então conferida ao fenômeno, foi criado em 1996, no estado do Rio de Janeiro, um serviço público especializado no desaparecimento de crianças e adolescentes: o SOS Crianças Desaparecidas (SOS). Inscrito na estrutura organizacional da Fundação

e Adolescentes Desaparecidos (Redesap), criada em 2002 e coordenada pela Secretaria de Direitos Humanos da Presidência da República; a Comissão Parlamentar de Inquérito que ficou conhecida como "CPI das Crianças Desaparecidas", instaurada em 2009 na Câmara dos Deputados; e, ainda, a Lei 11.259/2005, conhecida como "Lei da Busca Imediata", atualmente incorporada ao artigo 208 do ECA.

${ }^{3}$ As categorias "desaparecido" e/ou "pessoa desaparecida" recobrem um campo semântico relativamente amplo, caracterizado não só pela falta de consenso, mas também por disputas políticas e lutas sociais, conforme revelam estudos focados no caso brasileiro como Oliveira (2007), Araújo (2008, 2014) e Ferreira (2015a). A principal ambivalência presente nesse campo, no Brasil, deve-se ao fato de que ambas categorias são muitas vezes utilizadas para remeter tanto aos popularmente chamados "desparecidos políticos" quanto aos ditos "desaparecidos civis" - termo proposto por Oliveira (2007) e que pode ser aplicado aos casos de crianças e adolescentes desaparecidos tratados neste artigo-. Enquanto "desparecidos políticos" seriam as vítimas do crime de "desaparecimento forçado de pessoa", sistematicamente cometido durante o regime militar, tipificado pelo Direito Internacional e definido no âmbito do Tribunal Penal Internacional em abril de 1998, os "desaparecidos civis" protagonizariam processos, tramas e enredos muito variados, não recobertos por tipificações penais ou mesmo por categorias administrativas univocas, e dotados de pouca visibilidade e engajamento institucional para seu combate e prevenção no Brasil. Em trabalho anterior (Ferreira, 2015a) trato dessa questão e dos embates entre os agentes que buscam definir tanto as categorias "desaparecido" e "desaparecimento de pessoa", quanto as responsabilidades por elas geradas em casos de "desaparecidos civis". Para as finalidades do presente artigo, importa esclarecer que o tipo penal internacional "desaparecimento forçado de pessoa", diferente do que ocorre aos casos de "desparecidos civis", tem estatuto de crime contra a humanidade, e é definido como "a prisão, detenção ou seqüestro de pessoas por um estado ou por organização política, ou com a autorização, apoio ou aquiescência destes, seguidos da negativa de informar sobre a privação de liberdade ou dar informação sobre a sorte ou o paradeiro dessas pessoas, com a intenção de deixá-las fora do amparo da lei por um período prolongado." (Jardim 2011: 14). O Brasil foi condenado a legislar sobre a matéria pela Corte Interamericana de Direitos Humanos no Caso Gomes, Lund e outros, em sentença de 24 de novembro de 2010, mas o crime ainda não consta do ordenamento jurídico interno do país. Não obstante, a categoria tem sido aplicada, em instâncias variadas, não só aos casos de desaparecimento provocados por agentes de estado no período da ditadura militar, mas também a crimes cometidos após o processo de transição democrática, como demonstra Araújo (2014) a partir de etnografia realizada no Rio de Janeiro. Para uma discussão mais ampla sobre a categoria "desaparecido" em casos de desaparecimento forçado, que extrapola contextos nacionais e sustenta que ela consiste na figura da "vítima total e universal", ver Gatti (2011). 
para a Infância e Adolescência (FIA ${ }^{4}$, por sua vez vinculada à Secretaria de Assistência Social e Direitos Humanos (SEASDH) do estado, o SOS Crianças Desaparecidas atende regularmente familiares de meninas e meninos desaparecidos, cadastrando, divulgando e acompanhando seus casos. O programa tem como missão localizar as crianças e os adolescentes cujos desaparecimentos são lá reportados, além de difundir o que é designado, por seus funcionários e em todo o seu material de divulgação, como "cultura da identificação".

A difusão da "cultura da identificação" implica ações promovidas pelo SOS com vistas a alertar a população dos riscos acarretados pela circulação de crianças e adolescentes sem identificação por locais e eventos onde haja grande concentração de pessoas. Nessas ações, que ocorrem em rodoviárias, praias e eventos de grandes proporções, funcionários do programa distribuem pulseiras de identificação para uso imediato pelas crianças, além de folhetos e pequenas cartilhas que falam da importância da obtenção de registros de nascimento e de carteiras de identidade para crianças e adolescentes. Já a localização propriamente dita de desaparecidos, principal missão do SOS, é promovida através da divulgação sistemática de retratos desses meninos e meninas em cartazes produzidos pelo programa e distribuidos por todo o Brasil, além de outros suportes materiais e artefatos gráficos como, por exemplo, embalagens de pão, lacres de gás de botijão e contracheques de servidores públicos.

A partir de pesquisa etnográfica realizada no SOS Crianças Desaparecidas, no presente texto faço uma reflexão inicial acerca dos múltiplos efeitos provocados pela divulgação sistemática de retratos de meninas e meninos desaparecidos como a realizada pelo programa. ${ }^{5} \mathrm{~m}$

\footnotetext{
${ }^{4} \mathrm{~A}$ FIA é produto de algumas reestruturações legislativas e organizacionais que incidiram sobre a Fundação Estadual de Bem-Estar do Menor (FEBEM) do Rio de Janeiro. A FEBEM do Rio de Janeiro foi instituída em 1967. Em 1975, foi fundida com a Fundação Fluminense de Bem-Estar do Menor (FLUBEM), dando origem à Fundação Estadual de Educação do Menor (FEEM). Já em 1995, após a promulgação do ECA, a FEEM passou a ser denominada Fundação para a Infância e Adolescência (FIA). Desde então a FIA já esteve vinculada a diferentes secretarias estaduais: inicialmente vinculada à Secretaria de Estado de Trabalho e Ação Social, em 1999 passou a integrar a então criada Secretaria de Estado da Criança e do Adolescente (SECRIA), extinta no ano seguinte. Passou então a integrar a Secretaria de Estado de Ação Social e Cidadania (SASC), também extinta posteriormente. Em 2007, por fim, a Fundação foi inscrita no âmbito da Secretaria de Assistência Social e Direitos Humanos (SEASDH), a que pertence ainda hoje.

${ }^{5} A$ etnografia a que me refiro vem sendo conduzida no âmbito da pesquisa " $A$ administração burocrática de casos de crianças desaparecidas: formalidades,
} 
linhas gerais, argumento que a difusão de fotografias de crianças e adolescentes desaparecidos tem efeitos não só na trajetória particular de cada caso de desaparecimento assim divulgado, mas também nas biografias de crianças, adolescentes e outros sujeitos não envolvidos nos casos que se tornam alvo de intervenções por parte de serviços e órgãos públicos. Mais especificamente, busco demonstrar o papel tão sutil quanto determinante de certas categorias e julgamentos morais na definição de que outras crianças podem terminar por sofrer intervenções em consequência da circulação de retratos de meninas e meninos desaparecidos. Entendo o acionamento desses critérios como parte do quadro mais amplo de reprodução de desigualdades alimentado rotineiramente por práticas de intervenção estatal no campo da infância e juventude no Brasil.

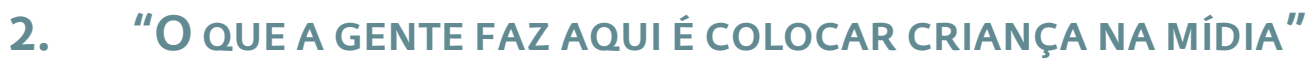

"A divulgação dos retratos dos meninos é nossa grande ação. O que a gente faz aqui é colocar criança na mídia". Com essas palavras, Maria ${ }^{6}$, técnica que é parte da equipe de dez funcionários que trabalha no SOS Crianças Desaparecidas, abriu uma conversa nossa a respeito de seus afazeres diários. A equipe que ela integra é composta por servidores públicos do estado do Rio de Janeiro com experiência prévia de atuação em diferentes programas de assistência social, e divide-se em dois grupos: os chamados técnicos, como a própria Maria, que são sete profissionais cuja atribuição principal é atender às pessoas que procuram pelo SOS; e os administrativos, que são três profissionais que se dedicam exclusivamente a tarefas de escritório (como atender telefonemas e manter os arquivos do programa organizados). Os técnicos são em sua totalidade assistentes sociais e psicólogos, ao passo que os administrativos são servidores públicos que não têm formação no que é chamado por eles próprios de área social. À frente da equipe está Gustavo, gerente do SOS desde seu primeiro dia de funcionamento. Diferente do restante da equipe, Gustavo tem formação em Educação

moralidades e disputas em um serviço público especializado", desenvolvida com o apoio do Conselho Nacional de Desenvolvimento Científico e Tecnológico (CNPq), por meio da Chamada Universal MCTI/CNPq n.14/2014.

${ }^{6}$ Os nomes próprios mencionados ao longo do artigo foram alterados para preservar a identidade de meus interlocutores de pesquisa e de todos os sujeitos envolvidos nos casos de desaparecimento descritos. 
Física, é servidor da Secretaria de Educação do estado do Rio de Janeiro, mas está cedido à SEASDH desde meados dos anos $1990 .^{7}$

Como me explicou na ocasião daquela conversa, Maria é responsável por distribuir de forma igualitária os rostos das crianças e adolescentes cujos desaparecimentos são reportados ao SOS nos cartazes (ver Figura 1) e demais formas de divulgação utilizadas pelo serviço. Para Maria, ainda que as ações em rodoviárias, praias e grandes eventos realizadas pelo SOS no âmbito da difusão da chamada "cultura da identificação" sejam relevantes, nada se compara ao alcance e à efetividade de "colocar criança na mídia" para a solução e a prevenção de casos de desaparecimento de crianças e adolescentes.

Figura 1. Exemplo de cartaz produzido e distribuído pelo programa (2013)

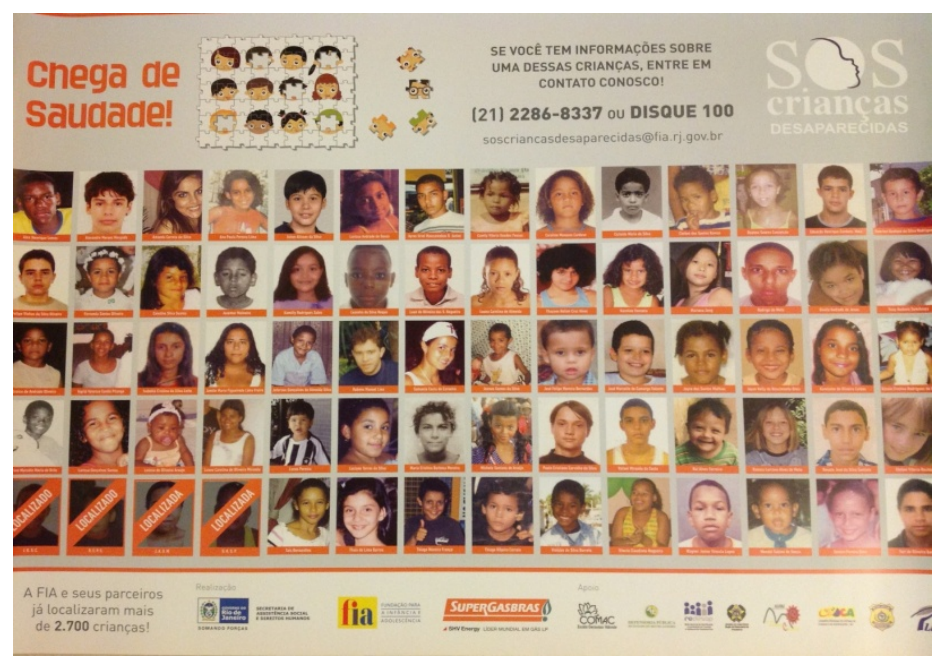

Desde janeiro de 1996, quando o SOS entrou em funcionamento, já foram reportados ao programa mais de três mil desaparecimentos de meninas e meninos de todas as idades. A maior parte dos casos ocorreu no estado do Rio de Janeiro, mas há também casos cadastrados lá que ocorreram em outras unidades da federação. Também desde que abriu

\footnotetext{
${ }^{7}$ Importa registrar que a trajetória profissional e de vinculação institucional de Gustavo, distinta da dos demais funcionários do SOS Crianças Desaparecidas, não opera no cotidiano como fator que o desqualificaria para a função. Gustavo goza de boa reputação dentro e fora da FIA, e a legitimidade de sua posição deve-se em larga medida à sua experiência à frente do programa, que coincide com o tempo de existência do próprio SOS. A história do programa, nesse sentido, é inteiramente atravessada por sua presença no cargo.
} 
suas portas, embora os cartazes sejam o principal meio de divulgação de retratos utilizado pelo SOS, convênios e parcerias temporárias têm permitido o eventual acionamento de outras formas de difusão de fotografias por parte do programa. Durante o período de meu trabalho de campo, por exemplo, o SOS contava com a parceria de duas emissoras de TV, um fornecedor de gás de botijão, uma empresa que confecciona embalagens de pão e alguns jornais locais, de pequena e média circulação. Além disso, divulgava fotografias de desaparecidos nos contracheques de servidores públicos do estado do Rio de Janeiro, o que incluía seu próprio corpo de funcionários.

"Colocar criança na mídia", através da circulação de seus retratos em todos esses suportes materiais de informação, gera o que Maria e os demais funcionários do SOS chamam de "denúncias": telefonemas, cartas e e-mails de pessoas que afirmam ter tido notícias ou visto pessoalmente alguma das crianças cujos rostos são divulgadas pelo programa. Logo que recebidas no SOS, essas denúncias têm sua credibilidade avaliada pelo corpo de funcionários. Algumas são objeto de crença e até mesmo de convicções que esses servidores públicos formam a respeito das crianças e adolescentes a que se referem, bem como acerca de seus autores, lá denominados "denunciantes". Há denúncias, por exemplo, que assim que recebidas são alvo de comentários como "isso é gente da família", "é pessoa que conhece a mãe" ou, ainda, "deve ser algum vizinho". Contudo, a grande maioria delas é considerada infundada, sendo a ocorrência de trotes e brincadeiras uma das maiores queixas dos funcionários do programa. Mesmo os trotes e as demais denúncias julgadas infundadas, contudo, são detalhadamente registradas pelos servidores do SOS em formulários e outros papéis que, acumulando-se no tempo, vão constituindo o que é por eles designado um caso de desaparecimento.

A depender das conclusões a que os servidores chegam acerca de sua credibilidade, as denúncias recebidas no programa são encaminhadas para os familiares das meninas e meninos desaparecidos em questão ou, em algumas ocasiões, apuradas pelos próprios funcionários e encaminhadas para policiais, conselheiros tutelares, promotores e defensores públicos considerados, nas palavras de Gustavo, "amigos do programa". O que o gerente denomina "amigos" do SOS são agentes públicos acionados não apenas por sua posição no sistema de garantia dos direitos da criança e do adolescente, mas principalmente por já 
terem atuado em algum caso reportado ao programa e/ou conhecerem pessoalmente algum de seus servidores. Ao designá-los "amigos", Gustavo destaca tanto o caráter personalista quanto o tom informal que enxerga nas relações entre o SOS e tais agentes. Quando realizado, o encaminhamento das denúncias aos "amigos do programa" é também registrado. Seus desdobramentos, todavia, não são acompanhados com sistematicidade.

Enquanto as fotografias são divulgadas, é comum que os familiares dos desaparecidos cujos casos chegaram ao conhecimento do SOS telefonem ou compareçam periodicamente ao programa. No mesmo sentido, é também prática regular que Maria, Gustavo e os demais servidores do SOS telefonem de tempos em tempos para esses familiares, entre outras razões para verificar se a criança ou adolescente em causa ainda está desaparecido. Eventualmente, acontece também de funcionários conduzirem "visitas domiciliares" às residências dos familiares dos desaparecidos para avaliar as "condições sócioeconômicas" em que vivem e produzir relatórios a respeito.

Tais contatos telefônicos, idas dos familiares ao programa e visitas domiciliares realizadas pelos funcionários são, em conjunto, considerados parte rotineira do que no sos é designado "acompanhamento dos casos". O acompanhamento de um desaparecimento perdura até que a criança ou adolescente em questão seja localizado. Essa localização pode decorrer de seu retorno espontâneo para o local de onde ele ou ela saíra antes de desaparecer, de buscas feitas pelos próprios familiares, ou, ainda, do trabalho de apuração de denúncias empreendido pelo próprio programa, pelos "amigos" do SOS, ou pela delegacia de polícia em que o caso também tenha sido reportado. Mesmo nos casos em que o desaparecido é encontrado morto e sua morte chega ao conhecimento dos servidores do programa, ele passa a ser considerado "localizado". Seja como for, a localização implica a suspensão definitiva da "grande ação" do SOS: a divulgação do retrato da criança ou adolescente "na mídia", para citar novamente a funcionária Maria.

Um exemplo de criança considerada localizada pelo SOS é o menino William. No final de 1997, quando o SOS tinha menos de dois anos de funcionamento, esteve lá o senhor Eduardo, camelô, morador de rua e pai de um menino de três anos chamado William. A mãe de William faleceu quando ele ainda era bebê, e desde então Eduardo tinha uma 
companheira, Marina, que o ajudava a criar o menino. Após uma briga violenta do casal, Marina tomou a decisão de não só deixar Eduardo, mas também separá-lo de seu filho. Em um ponto de ônibus na região portuária da cidade do Rio de Janeiro, Marina entregou William a um homem que, conforme apurado posteriormente, era um militar de reserva da Marinha. Na ocasião, ela teria dito ao militar que William sofria maus-tratos e diversas formas de agressão por parte de seu pai.

Até o ano de 2007, portanto durante os dez primeiros anos em que William esteve desaparecido, o SOS recebeu quatro denúncias relativas ao menino. Todas foram, por diferentes motivos, consideradas infundadas. Em 2011, porém, uma quinta denúncia foi recebida pela linha telefônica do programa e não só registrada, como também considerada procedente por seus funcionários. Segundo o denunciante, William, vivia em um pequeno município no norte fluminense com um casal que o teria adotado de forma irregular. Seu nome agora seria André, seu pai era militar de reserva da Marinha e sua mãe, enfermeira. A família teria se mudado às pressas para aquele município porque o garoto foi reconhecido em um cartaz do SOS na cidade em que viviam antes. O menino teria sido registrado como filho natural do casal, por meio de um processo amplamente conhecido como adoção à brasileira ${ }^{8}$.

Gustavo, gerente do SOS, e Carla, outra funcionária do programa, começaram então um processo de apuração da denúncia, tendo finalmente conseguido fazer contato com a enfermeira que, segundo o denunciante, seria agora mãe do menino. Na ocasião, e sem muita surpresa, ouviram da enfermeira a confirmação de que sim, ela havia registrado William como seu filho natural ainda nos idos de 1997, quando uma mulher entregara o menino aos cuidados de seu marido militar. Diante da confirmação das informações contidas na denúncia, o filho de Eduardo passou a ser considerado localizado pela equipe do SOS, que deu seu caso por encerrado e suspendeu a divulgação de sua fotografia. Desde então, o retrato do menino consta de alguns cartazes do programa com uma tarja alaranjada que o atravessa, em que se lê "localizado" (ver novamente Figura 1, detalhe no canto inferior esquerdo). Embora não tenham acompanhado os rumos tomados pelo caso desde então, servidores do programa acreditam que ele tenha tido desdobramentos judiciais importantes, já que a denúncia foi

\footnotetext{
${ }^{8}$ Para uma análise antropológica da adoção à brasileira, ver Fonseca (2006). 
encaminhada, pouco depois de recebida, a uma defensora pública e "amiga" do SOS.

\section{A FIGURA DA "CRIANÇA DESAPARECIDA"}

Uma das principais consequências da divulgação de cartazes e de outros suportes materiais usados para a difusão de retratos de meninas e meninos desaparecidos, "grande ação" do SOS Crianças Desaparecidas, consiste não apenas na eventual solução de casos individuais como o de William, mas também na produção e reprodução constante de um personagem social que se manifesta em múltiplos rostos, mas parece se sobrepor a eles e aos enredos que protagonizam: a "criança desaparecida" ${ }^{9}$. Esse personagem tem um caráter genérico, sendo capaz de reunir e indexar casos de desaparecimento cujas tramas variam enormemente: há episódios de adoção irregular, como ocorreu a William, mas há também histórias de recorrentes fugas do lar, de adolescentes que escaparam de instituições de acolhimento ou de cumprimento de medidas socioeducativas, de vítimas de crimes fatais, intempéries ou calamidades públicas cujos corpos não foram localizados, além de dramas de crianças que, envolvidas em conflitos de guarda, foram impedidas por um de seus pais de ter contato com o outro. Essa variedade de tramas e dramas indica que sob a face amplamente divulgada da "criança desaparecida", que aparece inclusive no nome do programa aqui analisado, estão enredos extremamente complexos e heterogêneos ${ }^{10}$.

Em um primeiro plano, isso indica que ao contrário da fragmentação de demandas e processos que caracteriza a atuação de órgãos, servidores e repartições públicas, muitas vezes com conseqüências nefastas (Arendt, 1999; Bauman, 1998), a atuação rotineira do SOS parece produzir o oposto: o englobamento de dramas muito distintos, cujas

\footnotetext{
${ }^{9} \mathrm{~A}$ ideia de que as formalidades e os procedimentos burocráticos empreendidos no sos produzem um personagem social inspira-se no trabalho de Vianna (1999) acerca da ação policial sobre os chamados menores vadios, abandonados ou delinqüentes no Rio de Janeiro do começo do século XX. A obra da autora revela que a construção do menor enquanto personagem social no contexto analisado decorre do saber, da autoridade e das funções policiais, exercidos cotidianamente na produção de classificações e destinos institucionais registrados em documentos.

${ }^{10}$ Essa variedade de enredos caracteriza o desaparecimento de pessoas em geral, e não apenas o de crianças e adolescentes (Ferreira, 2015a). Ademais, é ressaltada também em estudos sobre o desaparecimento de crianças e adolescentes em outros países, como mostram Biehal \& Jade (2000).
} 
particularidades são ocultadas em prol da produção de um personagem que se autonomiza em relação a histórias individuais. Nesse sentido, a atuação do SOS não apenas confirma, como leva às últimas conseqüências o fato de que cartazes e formas semelhantes de divulgação de fotos de crianças desaparecidas têm relativamente pouco impacto sobre a trajetória e o desfecho de casos específicos, embora sejam capazes de gerar comoção em torno do "problema" do desaparecimento de pessoas em geral (Lampinen et al., 2009).

Ainda que pouco auxilie na solução de casos individuais, porém, a autonomização da figura da "criança desaparecida" indica que a atuação do SOS é extremamente eficaz em produzir o grau de generalização necessário à criação, implantação e até mesmo avaliação de quaisquer políticas e serviços público-estatais. Se a Fundação para a Infância e Adolescência (FIA), instituição de que o programa é parte, lida com a "criança e o adolescente", o SOS, não há dúvida, dedica-se exclusivamente à "criança desaparecida". Distingue-se, desse modo, de outros programas da FIA, que lidam, por exemplo, com a "criança vítima de maus-tratos", com a "criança em situação de rua", ou com a "criança vítima de exploração sexual", entre tantos outros personagens. Embora não tenha capacidade propriamente descritiva, já que não contempla as especificidades dos casos reportados ao SOS, a "criança desaparecida" tem a capacidade de delimitar a área de competência do programa e conferir legitimidade a seus modos de atuação.

Mas se a figura da "criança desaparecida" incide sobre a estrutura institucional em que o SOS está inscrito, legitimando e justificando a existência do programa, ao mesmo tempo ela incide também sobre aqueles que procuram seus serviços, qualificando-as, com efeito, como "famílias de crianças desaparecidas". Os sujeitos e grupos assim qualificados não são simplesmente atendidos no SOS para, em seguida, retomar sua rotina. Ao contrário, no decurso dos procedimentos adotados como parte do acompanhamento dos casos, essas famílias são objeto de avaliação e comparação, tornando-se, por fim, um domínio de possivel intervenção - intervenção por parte não só do SOS, mas, potencialmente, também dos chamados "amigos do programa"-.

Assim que reportam um caso aos funcionários do SOS, por exemplo, essas famílias são necessariamente inquiridas, entre outras questões, sobre a incidência de alcoolismo, espancamento, uso de tóxicos, violência doméstica, abuso sexual e maus-tratos entre seus membros. 
Essas categorias estão impressas em um dos formulários que dão corpo aos casos cadastrados no programa, devendo ser respondida com a marcação de um $X$ caso incidam nas famílias dos desaparecidos em causa. O fato de cada uma dessas questões ser tematizada no atendimento prestado às famílias explicita os parâmetros a partir dos quais todas elas são avaliadas no SOS, além de revelar alguns dos elementos que compõem certo imaginário em torno da "criança desaparecida"11. Não obstante, embora tão reveladora, a tematização dessas questões é apenas um dos muitos procedimentos a que as famílias de crianças desaparecidas são submetidas quando procuram pelo programa.

Gradativamente, as familias tornam-se objeto de ações que se estendem por um continuum que vai desde telefonemas, conversas e processos sutis de aconselhamento muitas vezes demandados por elas, até as visitas domiciliares às quais são submetidas involuntariamente, que têm como finalidade averiguar as condições sócio-econômicas em que vivem, mas que são utilizadas também como formas de avaliar as expectativas e os sentimentos que o desaparecimento de um de seus membros possa ter provocado em suas relações. Tais ações explicitam com nitidez traços e temas do que Foucault (1990) denominou poder pastoral, incidindo sobre as famílias de crianças desaparecidas no sentido de reuni-las, guiá-las e conduzi-las. Como ouvi em certa ocasião de uma servidora do programa, "a gente precisa verificar, porque tem famílias que não têm condições de receber de volta uma criança".

Seja adentrando suas casas, seja tentando avaliar e governar seus afetos, expectativas e "condições", a atuação do SOS sobre as familias de crianças desaparecidas engendra o que Bourdieu (1996: 125) designa trabalho de instituição: o estabelecimento de um esquema classificatório que, sob a aparência de apenas descrevê-la, acaba por instituir a família como um corpo social específico. No SOS, contudo, a família instituída como corpo social específico é carregada da força do personagem que não só a qualifica, como também a conduz ao programa: a "criança desaparecida". É possível considerar, portanto, que

\footnotetext{
${ }^{11}$ Embora fuja ao escopo do presente texto, importa ressaltar que as chamadas famílias de crianças desaparecidas não são passivas diante deste e de outros procedimentos adotados no SOS Crianças Desaparecidas. Ao contrário, elas disputam os parâmetros formais e morais a partir dos quais são atendidas e avaliadas no programa, como sustento em Ferreira (2015b).
} 
a partir do desaparecimento de uma criança ou adolescente, uma família torna-se especialmente aparente -aparente não só porque documentada em um caso, mas também porque instituída e submetida a comparações e avaliações-.

Por um lado, os familiares, parentes e conhecidos de desaparecidos que buscam o programa são comparados à família pressuposta pelas categorias impressas nos formulários lá preenchidos: uma família em que há incidência de espancamento, alcoolismo, uso de tóxicos, violência doméstica, abuso sexual e/ou maus tratos ${ }^{12}$. Não obstante, por outro lado aqueles que buscam os serviços do sos são também submetidos a comparações com diferentes famílias enredadas nos casos através de denúncias feitas ao programa. Embora não tenham membros desaparecidos, e portanto não mantenham relação direta com nenhuma das crianças e adolescentes retratados em cartazes do SOS, essas famílias também se tornam alvo de ações do programa e, potencialmente, de seus "amigos".

\section{Retratos de UNS, EXPOSIÇÃO DE OUTROS}

Cada cartaz produzido e distribuído pelo SOS exibe cerca de setenta fotografias dispostas em linhas e colunas. Todas as fotografias contêm, abaixo do rosto da menina ou do menino retratado, seu nome completo. Em algumas edições desses cartazes, como evidencia o caso de William, há fotografias atravessadas pela tarja de "localizado", de modo a demonstrar a eficácia da divulgação de retratos nesses e em outros suportes materiais para a localização de desaparecidos. As demais fotografias, porém, lembram a todos que se detenham sobre elas que se há meninos e meninas que são finalmente localizados, outros tantos permanecem desaparecidos. Isso é reforçado, ainda, pelo próprio aspecto gráfico dos cartazes, que divulgam dezenas de fotografias

\footnotetext{
${ }^{12}$ Vale registrar que a relação entre categorias impressas em documentos oficiais e pressupostos sobre famílias e outras relacionalidades certamente não é exclusividade do SOS Crianças Desaparecidas, fazendo-se presente em repartições das mais diversas searas da administração pública. Muniz (1996), por exemplo, chama atenção para o fato de que também nas Delegacias de Atendimento à Mulher (DEAMs) onde realizou trabalho de campo categorias impressas em formulários (nesse caso, formulários que dão corpo a petições) revelam pressupostos sobre os conflitos que aportam naquelas repartições. Nas palavras da autora, "o modelo da petição e, sobretudo, a antiga ficha de atendimento (...) pressupõem que o agressor seja homem e que seja conhecido da vítima" (Muniz, 1996: 143).
} 
sempre justapostas, sempre no plural e sempre em tamanhos e formatos idênticos, sugerindo ao olhar do espectador não a construção de narrativas imagéticas que descreveriam individualmente as histórias de cada criança retratada, e sim um quase automático e sempre devastador efeito cumulativo (Sontag, 2003).

Em uma das muitas edições dos cartazes produzidos pelo SOS, colocada em circulação no final de 2012, encontra-se a foto de Bernardo, um menino que está desaparecido desde 2008. Filho do engenheiro José e da dona-de-casa Ângela, Bernardo desapareceu quando tinha cinco anos e estava brincando na casa de seus avós maternos. Isso aconteceu em julho de 2008, em uma cidade do interior do estado de São Paulo. O desaparecimento do menino foi registrado e investigado pela polícia local, além de divulgado naquele estado por iniciativas tomadas por José, pai de Bernardo. Um ano depois do desaparecimento, ainda sem notícias do menino, José procurou o SOS. Na ocasião, afirmou ter ido ao programa para solicitar especificamente que a foto de seu filho fosse incluida nos cartazes ali produzidos e distribuídos.

Também no final de 2012, o SOS fez uma campanha especial de divulgação de fotos de meninas e meninos desaparecidos em uma novela exibida pela Rede Globo de televisão -novela esta cujo protagonista era uma "criança desaparecida"- Durante uma semana, a foto de Bernardo foi exibida, ao lado de algumas outras, ao final dos capítulos diários do folhetim. Somente naquela semana, o SOS recebeu quatro denúncias relativas ao menino, confirmando a relação direta entre intensidade de exposição de retratos de desaparecidos e o número de "identificações", em sua maioria falsas, feitas por sujeitos que tenham contato com as fotografias (Lampinen et al, 2009). Nenhuma daquelas quatro denúncias foi julgada procedente. Semanas depois, porém, chegou ao SOS, por carta, uma denúncia que teve outro destino.

Na carta, a moradora de uma pequena cidade da serra fluminense relata ter visto uma criança muito parecida com Bernardo, o "lindo menino" cujo rosto conhecera ao final de um capítulo daquela que era sua novela predileta. Ela teria encontrado a criança em duas ocasiões diferentes, mas sempre em companhia da mesma mulher. Nas duas ocasiões, a criança "estava suja, irritada e parecia mal tratada", conforme diz a carta. Na primeira delas, chorava muito, o que motivou a denunciante a perguntar a razão do choro à mulher que o acompanhava, que teria 
respondido "que ele era assim nervoso porque era adotivo". Na segunda ocasião em que viu o menino, finalmente, a denunciante teria perguntado diretamente ele qual era seu nome e onde estudava, ao que o menino teria respondido prontamente: chamava-se Mauro e estudava na Escola Primavera.

Diferente das denúncias anteriores, a carta remetida ao SOS pela moradora da região serrana deu origem a um conjunto de medidas tomadas pessoalmente pelo gerente do programa. As estratégias narrativas, as categorias utilizadas e os valores morais acionados pela denunciante naquele documento encontraram ressonância na perspectiva e na conviç̧ão formadas por Gustavo acerca daquele caso, determinando não só a conformação de uma possível moralidade situacional (Eilbaum, 2012), como também o peculiar curso de ação por ele seguido. Em conjunto, a "sujeira", a "irritação" e o aparente "mau trato" atribuídos ao menino, somados à descrição de choro e a uma alegada adoção responsável por deixá-lo "nervoso", foram capazes de ecoar no SOS de tal forma que motivaram o gerente do programa a não só registrar o recebimento da carta, mas também a verificar pessoalmente sua veracidade.

Depois de ler a carta Gustavo encaminhou uma cópia para a uma defensora pública e "amiga do programa". Além disso, porém, decidiu viajar até a cidade de onde a carta foi remetida e visitar a escola onde o garoto Mauro estaria matriculado para, em suas palavras, "ver o menino com os próprios olhos". Nessa visita, mediante autorização da diretora da escola e da professora do garoto, Gustavo observou Mauro em diferentes atividades coletivas e recebeu cópias de documentos relativos à matrícula do menino, além de fotografias e um vídeo com imagens suas em uma festa junina da escola. A observação do garoto e a entrega dos documentos, das fotos e do vídeo pela diretora tinham como finalidade auxiliar Gustavo no exercício de identificar se Mauro é ou não Bernardo -exercício ao qual o gerente do SOS se dedicou por dias a fio-. Como não conseguisse chegar a nenhuma conclusão, Gustavo remeteu todo o material a uma "amiga do programa": uma delegada de polícia do estado do Paraná, que naquela época estava à frente de uma delegacia especializada que possui programas de computador que envelhecem fotografias e detectam faces. Atendendo ao pedido de Gustavo, as fotos e o vídeo foram examinados; o exame, contudo, foi inconclusivo. 
Já os documentos relativos à matrícula escolar do garoto tiveram consequências bastante distintas. Dentre esses documentos, havia a cópia de um termo de guarda provisória já vencido, que nomeava a avó materna de Mauro como sua guardiã. Esse documento em específico foi cuidadosamente analisado, copiado e remetido por Gustavo para uma defensora pública e "amiga do programa". Nas palavras de Gustavo, "mesmo o Mauro não sendo o garoto desaparecido, agora a defensora vai querer ver a situação dessa família aí, desse termo de guarda vencido; isso é irregular e ela quer averiguar".

Essas palavras de Gustavo evidenciam que a atuação do SOS, ao não só produzir e reproduzir a figura da "criança desaparecida", mas também estabelecer as "famílias de crianças desaparecidas" como um domínio de intervenção, tem a capacidade de expor à avaliação, comparação e regulação também outros sujeitos, unidades domésticas e parentelas que não aquelas que procuram o programa. Sujeitos e grupos enredados em casos de desaparecimento por denúncias motivadas pela divulgação de retratos em cartazes como os do SOS também podem, como foi o caso do menino Mauro e de sua avó, tornar-se alvo de ações e investigações que explicitam não apenas traços do poder pastoral, comentado anteriormente, mas também a ampla ideia de polícia recuperada por Foucault (1990): a polícia não como instituição, e sim como tecnologia de poder exercida nas mais diversas instâncias e searas do Estado.

o que o caso de Bernardo (e de Mauro) sugere de modo mais contundente, porém, é que essa tecnologia de poder não incide de forma igualitária sobre todas e quaisquer crianças, adolescentes e famílias. Ao contrário, é colocada em exercício a partir do acionamento de categorias e valores morais bastante específicos que, ao serem atribuídos a sujeitos também específicos, são capazes de persuadir e mobilizar servidores públicos, determinando o curso de suas ações.

\section{Múltiplas FACES, MúltiPLOS DESTINOS}

Reflexões acerca da administração policial e judicial de diferentes situações envolvendo crianças e adolescentes há muito têm chamado atenção para os efeitos definitivos que classificações, avaliações e decisões registradas em documentos confeccionados por funcionários de diferentes instituições provocam nas vidas de certas crianças, 
adolescentes e famílias. Os trabalhos de Vianna (1999, 2002), Villata e Ciordia (2010) e Lugones (2012) são exemplares nesse sentido. No âmbito das instituições analisadas por essas autoras, as interações entre policiais, operadores do direito, assistentes sociais, familiares e, algumas vezes, os próprios meninos e meninas em causa, revelam que o que fica (e o que não fica) registrado em documentos desempenha papel central na produção de "soluções possiveis" (Villalta e Ciordia, 2010) para a gestão de conflitos e destinos de crianças e adolescentes. Tais soluções impactam a vida daqueles à que se referem de modo tão decisivo que o contato posterior com documentos e prontuários a seu respeito, mesmo já na vida adulta, pode ser classificado como uma intensa "experiência marcante" (Schritzmeyer, 2014).

Os formulários, registros e denúncias que compõem casos de desaparecimento reportados ao SOS Crianças Desaparecidas também provocam efeitos decisivos nas vidas das meninas e meninos a que se referem sejam eles "crianças desaparecidas" cujos retratos são divulgados pelo programa ou não. A denúncia feita por carta referente ao desaparecimento de Bernardo, por exemplo, embora não tenha auxiliado na localização do menino, incidiu diretamente sobre a vida e o destino do garoto Mauro e de sua avó, demonstrando que se em determinados contextos cartas e outros papéis escritos têm a capacidade de produzir laços familiares (Padovani, 2013), no âmbito de serviços públicos como o SOS elas também podem expor, ameaçar e até provocar a ruptura dessas conexões.

Não obstante, outros artefatos gráficos que não os formulários, as cartas e os demais registros escritos que animam o cotidiano do SOS e são regularmente colocados em circulação por seus funcionários também incidem de modo determinante sobre laços familiares e sobre as vidas de crianças, adolescentes e outros sujeitos: os cartazes e demais suportes materiais utilizados para divulgar as fotografias dos desaparecidos. Ainda que não documentem sentenças, decisões escritas e "soluções possíveis" (Villalta e Ciordia, 2010) para situações e conflitos administrados judicialmente, cartazes, lacres de botijão de gás, contracheques e embalagens de pão que expõem as faces de crianças e adolescentes desaparecidos desempenham papéis decisivos em ações institucionais voltadas para determinados sujeitos, suas biografias e suas relações. Nesse sentido, aproximam-se de modo definitivo dos registros escritos oficiais, à medida que também parecem carregar "o 
duplo signo da distância e do entranhamento do estado na vida cotidiana" (Das e Poole, 2004: 15).

Além de fundamentais no processo de produção e reprodução da figura da "criança desaparecida", portanto, cartazes e demais formas de divulgação de retratos acionadas pelo SOS Crianças Desaparecidas provocam efeitos tanto sobre o curso individual de cada caso assim divulgado pelo programa, possibilitando sua solução por meio de denúncias, mas também sobre as vidas e as relações de outras crianças e adolescentes que não são reportados como desaparecidos nem para o programa, nem para quaisquer outros serviços e órgãos públicos. Os casos de William, solucionado a partir de uma denúncia motivada pela difusão do retrato do menino, e de Bernardo, não solucionado, mas objeto de uma carta que teve consequências importantes, exemplificam essas duas ordens de efeitos.

o caso de Bernardo, contudo, exemplifica ainda uma dimensão específica dos efeitos da divulgação de retratos de meninas e meninos desaparecidos no Brasil: o caráter decisivo das apreciações e julgamentos morais feitos pelos espectadores dessas fotografias em relação à aparência tanto das crianças e adolescentes cujas faces são estampadas em cartazes, quanto de outras crianças comparadas com as desaparecidas em busca de uma eventual identificação. Decisivo na carta referente a Bernardo, afinal, foi o esforço da autora e então denunciante em descrever as aparências tanto dele quanto de Mauro. Bernardo, como descrito na missiva, é um "lindo menino" cujo rosto foi divulgado, por dias seguidos, ao final dos capítulos diários de uma telenovela. Em contraste, Mauro, visto em ocasiões diferentes pela denunciante, seria um garoto que "parecia" não ser bem tratado e que circulava pela cidade "sujo" e "irritado".

Conforme descreve Eilbaum (2012: 235-288), "sujeira", "irritação" e aparência de "mau-trato" são categorias capazes de mobilizar funcionários de instituições e assim definir os destinos de famílias cujas trajetórias são definitivamente atravessadas por ações e intervenções institucionais. Especialmente em relação à categoria "sujeira", Schuch (2003) descreve também sua capacidade de demarcar separações simbólicas que operam de modo bastante efetivo na administração de conflitos envolvendo os chamados "adolescentes em conflito com a lei", como, por exemplo, a fronteira entre polícia e bandidos. Nesse mesmo sentido, na carta remetida ao SOS pela denunciante que viu o rosto do 
"lindo menino" Bernardo pela televisão, aquelas categorias lograram associar Mauro, a criança descrita como "suja, irritada e [que] parecia maltratada", a uma espécie de desordem e de desgoverno, distanciando-o da linda criança que ele teria sido antes de desaparecer. Assim, se por um lado Mauro se parecia com Bernardo, motivando a denunciante a redigir uma carta em que diz suspeitar de se tratarem do mesmo menino, por outro lado traços de sua aparência mais recente denotariam uma possivel situação de desgoverno inaugurada com seu desaparecimento ou até mesmo provocada por ele.

Esse desgoverno, na trajetória do caso de Bernardo, acabou sendo confirmado pelo termo de guarda vencido recebido, em cópia, pelo gerente do SOS Crianças Desaparecidas em sua visita à escola de Mauro. Como nos adverte Vianna (2014), certidões, relatórios e outros papéis que circulam por certas instituições "falam, de algum modo, da gestão de movimentações e, em especial, do poder de produzir fixações, de limitar e registrar errâncias, de conectar espaços e pessoas" (2014: 67). Porque vencido, aquele termo de guarda perdeu precisamente sua capacidade de limitar a errância, produzir fixação e conectar pessoas, e por essa razão tornou Mauro e sua avó alvos de possíveis ações e intervenções institucionais.

Meu trabalho de campo no SOS estava em pleno curso quando a carta que ligou Bernardo à Mauro foi recebida por seus funcionários. Pude, portanto, acompanhar os rumos tomados por aquele caso de perto, tendo me surpreendido não só com seu desfecho, mas sobretudo com a relativa naturalidade com que a decisão de ir à escola de Mauro "ver o menino com os próprios olhos", ainda que para isso tivesse que viajar por horas a fio, foi tomada pelo gerente Gustavo. Sem notar minha surpresa, contudo, Gustavo convidou-me a ir com ele até a cidade onde vivia o menino, acompanhando-o na intrincada tarefa de verificar se tratava ou não de Bernardo. Para o gerente, porque já havia escrito uma tese de doutorado acerca do desaparecimento de pessoas no Brasil, além de ter conduzido cursos de capacitação sobre o fenômeno para servidores públicos de diferentes estados, eu era uma especialista no tema que teria muito a contribuir na tentativa de identificação do menino ${ }^{13}$.

\footnotetext{
${ }^{13}$ Sobre a atribuição do estatuto de "especialista" no tema do desaparecimento de pessoas e sobre os cursos de capacitação que conduzi, ver Ferreira (2014).
} 
Embora eu já tivesse sido convidada e até convocada a participar de diferentes maneiras no campo da gestão do desaparecimento de pessoas no Brasil (Ferreira, 2014), o convite de Gustavo para participar da identificação de um menino que poderia ser uma "criança desaparecida" impactou-me a ponto de provocar certa paralisia. Afinal, diferente das muitas formas de participação em que já havia me engajado, aquele foi o único convite que recebi para tomar parte da trajetória de um caso particular de desaparecimento, e não de debates amplos e projetos gerais sobre o fenômeno. Acabei declinando do convite, não sem passar dias seguidos refletindo sobre os sentidos e os possiveis desdobramentos éticos e metodológicos de dizer "sim" ou "não" para Gustavo. Afinal, se a polícia como tecnologia de poder me parecia ser colocada em exercício naquela situação, o convite de Gustavo era, entre outras coisas, para que eu participasse de seu acionamento. Foi justamente a partir dessa reflexão que comecei a esboçar a discussão iniciada com o presente texto.

Se, por um lado, a divulgação de retratos de meninas e meninos desaparecidos tem efeitos ora sobre casos individuais, ora sobre outras crianças e famílias, por outro lado ela certamente impacta os próprios servidores públicos responsáveis por efetivá-la, assim como impactou meu trabalho de campo. Não só a divulgação, aliás, mas também a lida diária com dezenas de fotografias de rostos de crianças e adolescentes desaparecidos possivelmente têm consequências sobre esses funcionários públicos, que muitas vezes são interpelados não só pelas cartas, e-mails e outras formas utilizadas para veicular denúncias que recebem regularmente, mas também pelas próprias imagens e por relatos e descrições das aparências tanto de "crianças desaparecidas", quanto de outras crianças. O que a situação em torno de Bernardo e de Mauro aponta, não obstante, é que o mais desafiador nesse processo parece ser o fato de que tais relatos e descrições aportam no SOS carregados de apreciações e julgamentos morais tão sutis quanto efetivos.

\section{CONSIDERAÇÕES FINAIS}

Em certa passagem da obra Diante da dor dos outros, ao se referir a uma série de fotografias de guerra, Susan Sontag afirma que "há muitos usos para as inúmeras oportunidades oferecidas pela vida moderna de ver à distância, por meio da fotografia - a dor de outras pessoas" (2003: 16). 
Para a autora, se por um lado o contato visual com a dor dos outros pode provocar tanto compaixão quanto repugnância, por outro ele não pode deixar de suscitar perguntas sobre as crueldades de cenas e dramas que não são retratados nem divulgados por meio da fotografia. O texto que ora encerro é uma tentativa, ainda inicial, de levar a sério essas considerações de Sontag (2003) diante não de fotografias de guerra, mas de retratos de meninas e meninos desaparecidos que são sistematicamente divulgados por serviços públicos como, por exemplo, o SOS Crianças Desaparecidas (SOS) do Rio de Janeiro. Encarada como "grande ação" de programas como o SOS, a divulgação de fotografias é uma estratégia utilizada regularmente para a localização de crianças e adolescentes considerados desaparecidos não só por suas famílias, mas também por tais serviços públicos.

A promulgação do Estatuto da Criança e do Adolescente (ECA) no Brasil, em meados do ano de 1990, tornou a provisão de serviços que promovam a localização de meninas e meninos desaparecidos parte integrante da política de atendimento à criança e ao adolescente no Brasil, engendrando a criação de diversas iniciativas, programas, ações e órgãos inscritos em diferentes searas da administração pública. O SOS Crianças Desaparecidas, cuja atuação foi analisada aqui, inscreve-se no âmbito da Secretaria de Assistência Social e Direitos Humanos do estado do Rio de Janeiro. Um órgão do estado do Paraná e considerado "amigo do programa", porém, é o Serviço de Investigação de Crianças Desaparecidas (SICRIDE), que tem estatuto de delegacia e é vinculado à Secretaria de Segurança Pública e Administração Penitenciária daquele estado. Também em Minas Gerais, a Delegacia Especializada de Localização de Pessoas Desaparecidas, que lida com desaparecimentos de crianças e adolescentes, mas também de adultos e idosos, é mais um órgão que atende à determinação do ECA e é situado na seara da segurança pública. O mesmo ocorre em São Paulo, onde a Delegacia de Homicídios e Proteção à Pessoa oferece a população serviços especializados na busca de crianças e adolescentes desaparecidos.

O desaparecimento de pessoas -e, em especial, o de crianças e adolescentes - é um problema social definido como tal por meio de controvérsias, embates e acusações cruzadas de responsabilidade estabelecidas entre instituições e agentes sociais variados. O debate sobre a área de competência em que o fenômeno se inscreve, em que assistência social e segurança pública são colocadas em oposição, é 
parte fundamental dessas controvérsias, e incide diretamente sobre a forma como tanto policiais quanto assistentes sociais lidam com casos particulares que lhes são reportados por pais, mães, irmãos e conhecidos de meninas e meninos desaparecidos (Ferreira, 2015a). Sendo o próprio episódio de desaparecimento de seus filhos, irmãos e conhecidos causa de dor e preocupação, as interações desses sujeitos com funcionários de diversas instituições parece agravar de modo incontornável suas angústias, atualizando o fato de o sofrimento ser uma experiência social passivel de ser intensamente reforçada pelas respostas oferecidas por poderes políticos, econômicos e institucionais a determinados problemas sociais (Kleinman et al, 1997: ix). Parte desse reforço, como indica o desfecho do caso de Bernardo, é consequência não da suposta separação entre os universos da assistência social e da segurança pública, tão acionada em debates acerca do desaparecimento de pessoas no Brasil, e sim o contrário: a porosidade e até receptividade do primeiro a tecnologias de poder normalmente associadas ao último.

O que busquei destacar aqui foi de que forma outras crianças, adolescentes e famílias que não aquelas diretamente envolvidas em casos de desaparecimento reportados a serviços como o SOS Crianças Desaparecidas são enredadas nessas tramas e têm suas vidas e relações expostas a possiveis ações e intervenções institucionais, tornando-se também sujeitos de experiências de sofrimento. Mais especificamente, busquei sustentar que a divulgação de retratos das meninas e meninos desaparecidos cujos casos são cadastrados e divulgados por esses serviços desempenha papel crucial nesse enredamento, em razão de uma dimensão peculiar da forma como os espectadores dessas fotografias reagem ao que vêem: produzindo apreciações e julgamentos morais das aparências tanto das crianças e adolescentes nelas retratados, quanto de outros "sujeitos de direitos" que são com eles comparados em busca de uma eventual identificação. Essas apreciações e julgamentos tornam-se, a meu ver, parte dos critérios a partir dos quais são definidos que meninos, meninas e famílias são suscetiveis a ações e intervenções institucionais, operando como parte de um amplo quadro de produção e reprodução de desigualdades que têm acompanhado a implementação dos chamados "direitos da criança" no Brasil. 


\section{BIBLIOGRAFIA}

Araújo, F. A. (2008). Falta alguém na minha casa. In R. Kant de Lima (Ed.), Antropologia e Direitos Humanos 5 (pp.166-225). Brasília: Booklink:

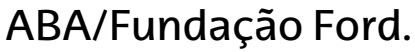

Aráujo, F. A. (2014). Das técnicas de fazer desaparecer corpos: desaparecimento, violência, sofrimento e política. Rio de Janeiro: FAPERJ/Lamparina.

Arendt, H. (1999). Eichmann em Jerusalém: um relato sobre a banalidade do mal. São Paulo: Companhia das Letras.

Bauman, Z. (1998). Modernidade e Holocausto. Rio de Janeiro: Jorge Zahar Editor.

Biehal, N., \& Wade, J. (2010). Going Missing from Residential and Foster Care: linking biographies and contexts. British Journal of Social Work, 30, 211-225.

Bourdieu, P. (1996). Razões Práticas: sobre a teoria da ação. Campinas: Papirus.

Brasil (1990). Estatuto da Criança e do Adolescente. Lei N.8.069/1990.

Cardarello, A. (1996). Implantando o Estatuto: um estudo sobre a criação de um sistema próximo ao familiar para crianças institucionalizadas na FEBEM/RS. Dissertação de mestrado em Antropologia Social na Universidade Federal do Rio Grande do Sul. Porto Alegre: PPGAS/UFRGS.

Das, V., \& Poole, D. (2004). State and its margins: comparative ethnographies. In V. Das \& D. Poole (Eds.), Anthropology in the Margins of the State (pp. 3-33). Santa Fe: SAR Press.

Eilbaum, L. (2012). "O Bairro Fala": conflitos, moralidades e justiça no conurbano bonaerense. São Paulo: Hucitec/ANPOCS.

Ferreira, L. C. de Mesquita. (2014). O etnógrafo, o burocrata e o "desaparecimento de pessoas" no Brasil: notas sobre pesquisar e participar da formulação de uma causa. In S. R. R. Castilho, A. C. Souza Lima \& C. Teixeira (Eds.), Antropologia das práticas de poder: reflexões etnográficas entre burocratas, elites e corporações (pp. 127149). Rio de Janeiro: ContraCapa.

Ferreira, L. C. de Mesquita. (2015a). Pessoas Desaparecidas: uma etnografia para muitas ausências. Rio de Janeiro: Editora UFRJ.

Ferreira, L. C. de Mesquita. (2015b). Formalidades, moralidades e disputas de papel: a administração de casos de crianças desaparecidas no Rio 
de Janeiro. Dilemas: Revista de Estudos de Conflitos e Controle Social, $8(2)$, abr/mai/jun, 207-234.

Fonseca, C. (2006). Da circulação de crianças à adoção internacional: questões de pertencimento e posse. Cadernos Pagu, 26, 11-43.

Foucault, M. (1990). Omnes et singulatim: por uma crítica da razão política. Novos Estudos, 26, 77-99.

Gatti, G. (2011). De un continente al otro: el desaparecido transnacional, la cultura humanitaria y las víctimas totales en tiempos de guerra global. Politica y Sociedad, 48(3), 519-536.

Gregori, M. F., \& Silva, C. S. (2000). Meninos de rua e instituições: tramas, disputas e desmanche. São Paulo: Contexto.

Jardim, T. Dal Maso. (2011). Brasil condenado a legislar pela Corte Interamericana de Direitos Humanos: da obrigação de tipificar o crime de desaparecimento forçado de pessoas. Brasília: Centro de Estudos da Consultoria do Senado/Textos para discussão, n. 83.

Kleinman, A., Das, V., \& Lock, M. (Eds.). (1997). Introduction. In Social suffering (pp. i-xxvii). Berkeley: University of California Press.

Lampinen, J. M., Arnal, J., \& Hicks, J. L. (2009). The Effectiveness of Supermarket Posters in Helping to Find Missing Children. Journal of Interpersonal Violence, 24, 406-423.

Lugones, M. G. (2012). Obrando en autos, obrando em vidas: formas y fórmulas de protección judicial en los tribunales prevencionales de menores de Córdoba, Argentina, a comienzos del siglo XXI. Rio de Janeiro: E-Papers.

Muniz, J. (1996). Os direitos dos outros e outros direitos: um estudo sobre a negociação de conflitos nas DEAMS/RJ. In L. E. Soares (Org), Violência e Política no Rio de Janeiro (pp.125-164). Rio de Janeiro: ISER/Relume Dumará.

Oliveira, D. D. (2007). Desaparecidos civis: conflitos familiares, institucionais e de segurança pública. Tese de Doutorado. Brasília: Instituto de Ciências Sociais, Departamento de Sociologia, UnB.

Padovani, N. C. (2013). Confounding Borders and Walls: Documents, letters and the governance of relationships in São Paulo and Barcelona prisons. Vibrant: Virtual Brazilian Anthropology, 10(2), 340-376.

Schuch, P. (2003). Trama de significados: uma etnografia sobre sensibilidades jurídicas e direitos do adolescente no Plantão da Delegacia do Adolescente Infrator e no Juizado da Infância e da 
Juventude de Porto Alegre/RS. In R. Kant de Lima (Org.), Antropologia e Direitos Humanos 2 (pp.157-202). Niterói: EDUFF.

Schuch, P. (2009). Práticas de justiça: antropologia dos modos de governo da infância e juventude no contexto pós-ECA. Porto Alegre: Editora da UFRGS.

Schritzmeyer, A. L. P. (2014). Fios da vida: crianças abrigadas, hoje adultas, diante de seus prontuários. Trabalho apresentado na $29^{a}$ Reunião Brasileira de Antropologia. Natal, 3 a 6 de agosto de 2014.

Sontag, S. (2003). Diante da dor dos outros. São Paulo: Companhia das Letras.

Vianna, A.de R. B. (1999). O mal que se adivinha: polícia e menoridade no Rio de Janeiro, 1910-1920. Rio de Janeiro: Arquivo Nacional.

Vianna, A.de R. B. (2002). Os limites da menoridade: responsabilidade, tutela e familia em julgamento. Tese de doutorado. Río de Janeiro. Programa de Pós-Graduação em Antropologia Social do Museu Nacional/UFRJ.

Vianna, A. de R. B. (2014). Etnografando documentos: uma antropóloga em meio a processos judiciais. In S. R. R. Castilho, A. C. Souza Lima \& C. Teixeira (Eds.), Antropologia das práticas de poder: reflexões etnográficas entre burocratas, elites e corporações (pp. 43-70). Rio de Janeiro: ContraCapa.

Villalta, C., \& Ciordia, C. (2010). Administrando soluciones posibles: medidas judiciales de protección de la niñez. Avá: Revista de Antropología, 18, 111-131. 